\title{
Las ofrendas de fauna en tumbas argáricas: nuevas perspectivas desde La Almoloya y La Bastida (Murcia)*
}

\author{
Faunal offerings in Argaric tombs: new perspectives from La Almoloya and La Bastida \\ (Murcia)
}

\section{Lourdes Andúgara ${ }^{\mathrm{a}}$ Eva Celdrána ${ }^{\mathrm{a}}$, M. ${ }^{\mathrm{a}}$ Inés Fregeiro ${ }^{\mathrm{a}}$, Vicente Lull ${ }^{\mathrm{a}}$, Rafael Micó Pérez ${ }^{\mathrm{a}}$, Camila Oliart $^{\mathrm{a}}$ y Cristina Rihuete Herrada ${ }^{\mathrm{a}}$}

\section{RESUMEN}

Los restos de fauna, escasa o dudosamente documentados en tumbas del Grupo Argárico, han cobrado relevancia en los últimos años al amparo del concepto "comensalidad". El objetivo de este trabajo es revisar su aplicación en las interpretaciones actuales, así como explorar nuevas vías de análisis a partir de los registros de La Almoloya y La Bastida (Murcia). Los resultados indican que la asignación de porciones faunísticas fue una práctica frecuente y socialmente transversal, que solo excluyó de forma significativa a la población infantil y que, con el tiempo, se hizo más restrictiva. Más que indicadoras de distancia socioeconómica, las ofrendas faunísticas tuvieron un sentido político: la donación de "alimento" resultó clave en el reconocimiento social de buena parte de los miembros de las comunidades argáricas.

\begin{abstract}
The faunal remains found in Argaric graves have been scarcely or poorly documented. In recent times, however, they have been gaining interest under the spotlight of the concept 'commensality'. The aim of this paper is to review its application in current interpretations, and to explore new analytical avenues taking into account the archaeological records of La Almoloya and La Bastida (Murcia, Spain). Our results show that the deposition of faunal portions was a widespread social practice, from which only children were mostly excluded. Moreover, a trend towards increasing restrictions to fau-
\end{abstract}

nal offerings in late Argaric times is also suggested. Rather than considering faunal grave goods as markers of economic asymmetries, they are better understood in the political domain: offering 'food'was crucial in the recognition of membership in the Argaric communities.

Palabras clave: El Argar; Edad del Bronce; La Almoloya; La Bastida; conjuntos funerarios; zooarqueología; comensalidad.

Key words: El Argar; La Almoloya; Bronze Age; La Bastida; funerary assemblages; zooarchaeology; commensality.

\section{RESTOS DE FAUNA EN AJUARES FUNERARIOS ARGÁRICOS: LOS TÉRMINOS DE UN DEBATE}

\subsection{El registro funerario argárico: notas sobre representación y significado}

La mayor parte del registro funerario argárico se compone de inhumaciones individuales intramuros. En estos conjuntos cerrados, la sociedad canceló el uso de ciertos objetos y, por tanto, renunció para siempre a intervenir físicamente en ellos y con ellos. Los dispuso junto a una persona muerta que, aunque parezca el sujeto del funeral, en realidad era el objeto de una

* Este trabajo ha contado con financiación de los proyectos: "Genealogías y redes en El Argar (2200-1550 cal ANE)" (Ministerio de Industria, Economía y Competitividad MINECO, HAR2017-85962-P), Grup de Recerca en Arqueoecologia Social Mediterrània - Universitat Autònoma de Barcelona ASOME-UAB (Agència de Gestió d'Ajuts Universitaris i de Recerca AGAUR, 2017SGR1044) y Consejería de Turismo y Cultura de la Región de Murcia (ARQ 129/2018 y 130/2018).

a Grup de Recerca en Arqueoecologia Social Mediterrània - Universitat Autònoma de Barcelona (ASOME-UAB). Dept.de Prehistòria, Mòdul de Recerca A. Avinguda de Can Domènech. 08193 Bellaterra (Cerdanyola del Vallès, Barcelona). Correos e.: LA luandugar@gmail.com https://orcid.org/0000-0003-2571-9639; EC eva.celdran@uab.cat https://orcid.org/0000-0002-8571-6459; MIF mifregeiro@gmail.com https://orcid.org/0000-0003-3611-5363; VL Vicenc.Lull@uab.cat https://orcid.org/0000-0002-2974-5087; RMP Rafael.Mico@uab.cat https://orcid.org/0000-0002-2957-3182; CO camila.oliart@uab.cat https://orcid.org/0000-0002-4857-7218; CRH Cristina.Rihuete@uab.cat https://orcid.org/0000-0003-1535-0209

Recibido 14-X-2020; aceptado 15-II-2021. 
práctica social. El sujeto fue la sociedad y, su excusa, un cuerpo inerte.

Es pertinente preguntarse: ¿qué expresaba la sociedad en esas tumbas? Su composición revela regularidades, tal vez una sintaxis, de forma que cada sepultura podría ser asimilada a una oración. En el ritual funerario, el sujeto no era el cadáver, sino la sociedad. Ahora bien, sí lo fue cuando centramos el análisis en el interior de la sepultura. Este, transfigurado en objeto clave o "primordial" (Lull 2007: 226-229), atrajo a otros objetos a modo de complementos. En la sociedad argárica, no todos los objetos y los sujetos se consideraron adecuados en la sintaxis funeraria intramuros. Además, entre los objetos potencialmente aptos, solo algunos acababan en una tumba concreta. La reunión de objetos en tumbas componía relaciones sintagmáticas de mayor o menor extensión. Recordemos que, en lingüística, la función sintagmática amplía el significado por adición de nuevos elementos.

Complementos o predicados, los objetos depositados en tumbas conciertan lo social de una vida/muerte individual. Su reunión expresa dos recorridos vitales. El primero concierne a los "objetos de pertenencia", aquellos vinculados al cuerpo de ciertos sujetos que siguen acompañándolo en la sepultura. El segundo se refiere a los "objetos de pertinencia", aquellos que la sociedad considera oportuno asociar a ciertos grupos de personas. La frontera entre "pertenencia" y "pertinencia" es difusa, pero se aclara si tenemos en cuenta que lo "pertinente" no subraya lo propio de un individuo, sino un protagonismo social exterior a este. Por otro lado, "pertenencia" enfatiza lo propio-individual evitando expresamente la categoría "propiedad", ya que esta designa una relación que no puede ser certificada únicamente desde los conjuntos funerarios.

En los ajuares funerarios argáricos se distinguen tres clases de objetos: vestimenta y adornos, armas e instrumentos metálicos, y ofrendas relacionadas con la alimentación. Las dos primeras incluyen objetos de pertenencia, que vinculan las personas enterradas con la consideración social que se les brindó en vida. La sociedad argárica inhumaba cadáveres vestidos y, con frecuencia, envueltos a modo de fardo, según se desprende de la tafonomía esquelética. Que se inhumaban vestidos lo sabemos gracias a algunos contextos con condiciones de preservación extraordinarias ${ }^{1}$, e indirectamente, por restos de tejido, lino preferentemente, adheridos a la superficie de objetos de cobre, o por botones de marfil que, a veces, se teñían de rojo por contacto con la ropa (Siret y Siret 1887: 157, lám. 41, nº 202; López Padilla 2006: 98; Jover y López Padilla 2003)

\footnotetext{
${ }^{1}$ Nos referimos a la sepultura 121 de Castellón Alto (Molina et al.
} Trab. Prehist., 78, N. ${ }^{\circ}$ 1, enero-junio 2021, pp. 104-120, ISSN: 0082-5638 https://doi.org/10.3989/tp.2021.12267
2013). Los adornos personales completaban el atuendo. Por su parte, las armas e instrumentos metálicos parecen indicar una "extensión" de las personas según condicionantes sociales relacionados con el sexo y la clase. Son, por tanto, "objetos de pertenencia".

Además de ropa, adornos, armas e instrumentos, pudieron depositarse comestibles. Se han recuperado restos y/o los recipientes que presuntamente o, con certeza, los contuvieron ${ }^{2}$. Este último grupo de materiales responde a motivaciones y protocolos diferentes. Así, mientras que la vestimenta, los adornos y el equipo instrumental podrían haber sido usados en vida hasta ser indicadores para el reconocimiento social de ciertas personas, los alimentos y sus eventuales contenedores se ajustan a la definición de "ofrenda": son donados por la sociedad para fines rituales. Esto explicaría su aparición en solitario en algunas tumbas e, incluso, en cenotafios $^{3}$. Son, por tanto, "objetos de pertinencia".

\subsection{La fauna en ajuares funerarios argáricos: estado de la cuestión, problemáticas y objetivos}

La arqueología argárica ha prestado una atención especial a los objetos de pertenencia y de pertinencia documentados en sepulturas, ya sea analizándolos por separado o considerando el ajuar en su conjunto (Lull y Estévez 1986; Cámara 2001; Lull et al. 2005; Aranda y Molina 2006). Sin embargo, los restos faunísticos han quedado al margen hasta fecha reciente (Liesau y Schubart 2004; Aranda y Esquivel 2006, 2007; Aranda y Montón 2011; Aranda 2016). Se sabía que las porciones faunísticas fueron contempladas en la sintaxis funeraria, pero las dificultades o incertidumbres asociadas a su recogida y correcta documentación las habían relegado a un papel marginal o nulo en la investigación.

La primera consecuencia de esta desatención es que ignoramos la función sintagmática de la fauna en la representación funeraria: qué sujetos merecieron este complemento y en qué circunstancias, y cuáles no. Por tanto, está por determinar si las ofrendas alimentarias fueron depositadas al azar o conforme a normas. Uno

\footnotetext{
${ }^{2}$ Ya en los inicios de la arqueología argárica Rogelio de Inchaurrandieta (1870: 810) escribía a propósito de sus hallazgos en La Bastida: "De las urnas [funerarias] se extraen ollas y vasos de formas muy diversas, que contienen mandíbulas y huesos de varios animales, probablemente restos de alimentos que depositaban junto a los muertos. Algunos pucheros, que solo tienen tierra, pueden haber contenido carne". Análisis recientes sobre residuos orgánicos han identificado sustancias alimenticias en numerosos recipientes cerámicos (Parras et al. 2011; Molina 2015).

${ }^{3}$ Véase Lull (2016: 16) sobre la consideración funeraria de los cenotafios, que justifica su inclusión en el presente análisis.
} 
de los objetivos del presente trabajo es aclarar esta cuestión.

La segunda consecuencia afecta a la categoría "fauna", en la medida en que acoge una multiplicidad de cualidades según sus dimensiones taxonómica y anatómica. Ambas abren la función paradigmática. En lingüística, la función paradigmática, a diferencia de la sintagmática, procede mediante conmutación al proporcionar respuestas intercambiables. En nuestro caso, opera una vez dada la función sintagmática de "fauna" y la amplía al ofrecer un abanico de posibilidades según la especie seleccionada y la o las partes anatómicas depositadas. La función paradigmática es responsable de una nueva apertura significante. Sobre los datos taxonómicos y anatómicos que la posibilitan, se han realizado los citados estudios recientes, al hilo del interés en los ajuares alimenticios en otros periodos y regiones de la prehistoria reciente peninsular (Garrido et al. 2011; Garrido 2012-2013; Costa et al. 2019).

En el caso argárico, la muestra analizada hasta el momento procedía de casi 60 tumbas, la mayoría de los yacimientos de Fuente Álamo (Almería), el casco urbano de Lorca y Los Cipreses (Murcia), y los granadinos Cerro de la Encina y Cuesta del Negro (Aranda 2016; Aranda y Montón 2011). Según sus conclusiones, la deposición de porciones cárnicas se efectuó en el marco de ceremonias donde se consumieron alimentos, y en las que la posición social de la persona fallecida influyó en la selección de la especie animal sacrificada. Las porciones de vacuno, animales de alto valor, quedaban reservadas a los miembros de la clase alta y, ocasionalmente, a otros situados por debajo en la escala social aunque deseosos de ascender. En cambio, la colocación de porciones de ovejas y cabras sería característica de los grupos sociales más pobres.

En buena parte de los estudios recientes, los restos faunísticos en tumbas suelen entenderse al amparo del concepto "comensalidad". Este es un término desafortunado, no solo porque la Real Academia Española de la Lengua lo ignora, sino por el sesgo de su carga semántica. Se asocia etimológicamente a "comensal", aplicado tanto a eclesiásticos al servicio de prelados como a personal dependiente de la familia real, libre de cargas de tutela y alojamiento. Según el derecho eclesiástico, su uso designa la relación entre el obispo y el ordenado por él y obliga, al primero, a sustentar en su mesa al segundo ${ }^{4}$. En resumen, un trasunto humanista de corte religioso, cuyo campo semántico se extendió posteriormente a la relación biológica en que una especie se alimenta a expensas de otra ("comensalismo").

\footnotetext{
4 Voces "comensal", "comensalía", "comensalismo" y "comensalidad", en Enciclopedia Universal Ilustrada Europeo-americana (19081930) XIV. Espasa-Calpe. Madrid.
}

Teóricamente, podría prescindirse de esta carga semántica y limitar el significado de "comensalidad" a lo que su raíz latina indica: "personas que comen conjuntamente (cum) en la misma mesa (mensa)" o "personas que comparten mesa", una situación que la Real Academia Española recoge como "comensalía". Ello parece difícil porque "comensalidad" procede de una traducción literal del inglés commensality, arraigada por un hábito que, de manera acrítica, arrastra aquella denotación de corte jerárquico y, también, la biológica de dependencia o parasitismo. Aun así y pese a la popularidad de "comensalidad", hay quien prefiere feasting, un término seguramente más ajustado porque no prejuzga la dependencia de unos (invitados) con respecto a otros (anfitriones jerárquicos) ${ }^{5}$. Feasting, en su acepción más general, alude a reuniones en las que se consumen bienes en abundancia. Ahora bien, feasting añade una connotación según la cual el acto de consumo no se reduce a lo estrictamente biológico, sino que es la excusa u ocasión para el juego político y sus implicaciones ideológicas.

Lo más apropiado para versionar feasting cuando el consumo gira en torno a alimentos y bebidas podría ser "banquete". ¿Hablaríamos entonces de "banquetes funerarios"? En el caso argárico se infiere, a nuestro juicio problemáticamente, la celebración de tales acontecimientos a partir del hallazgo de porciones de fauna en cierto número de sepulturas. Ahora bien, cambiar el signo de lo que se deposita, en sentido estricto porciones faunísticas, quizá raciones de carne, por un indicador inequívoco de lo que se intuye o imagina (residuo o símbolo de un banquete funerario imbuido de sentido político-ideológico), requeriría el apoyo de evidencias independientes, concretamente acumulaciones de restos producto de dicho evento colectivo en los conjuntos funerarios o en depósitos arqueológicos vinculados con estos. Sin embargo, semejante apoyo empírico resulta por ahora nulo, un aspecto subrayado también por distintos autores (Cámara y Molina 2009, 2011). Los estudios recientes sobre fauna en tumbas no aportan datos que documenten esa eventualidad, como tampoco hay rastro de ellos en excavaciones realizadas en los últimos años (La Almoloya, La Bastida).

Por tanto, sospechamos que se ha procedido a una doble sobrelectura: la primera, derivada de un principio de autoridad sustentado en casos etnográficos evocados a fines comparativos (pese a saberse que la etnografía brinda ejemplos para casi todo); la segunda, al avalar una interpretación en clave de "comensalidad" prescindiendo de los testimonios arqueológicos que habrían de sustentarla. Estas apuestas hermenéuti-

\footnotetext{
5 En rigor, "comensalidad" no podría aplicarse a sociedades igualitarias, tan prolijas en comidas comunitarias.
} 
cas descuidan la base empírica, si es que no la obvian por completo. Se trata de lecturas, en ocasiones ricas e imaginativas, que ilustran la manera de historiar que acompaña al capitalismo tardío (en célebre expresión de F. Jameson 1991). Su característica es facilitar "atajos": tras una mirada impaciente sobre ciertas clases de objetos arqueológicos, la inspiración o la evocación sustituyen al seguimiento de un método explícito como guía de la narración.

El presente trabajo rechaza la inspiración etnográfica y el salto interpretativo que suele acompañarla en arqueología, y opta por justificar inferencias ancladas en la materialidad de los conjuntos funerarios. Sus objetivos se sitúan en dos dimensiones.

1. Establecer la relación, si la hubo, entre las ofrendas faunísticas y los cuerpos que las merecieron, según las variables de edad, sexo y clase social.

2. Definir las particularidades taxonómicas y anatómicas de estas ofrendas y, en segunda instancia, las eventuales relaciones entre dichas particularidades y las variables de edad, sexo y clase social de los individuos asociados.

\section{MATERIALES Y METODOLOGÍA (Anexo)}

El material que ha de permitir alcanzar estos objetivos procede de La Almoloya (Pliego-Mula) (AnexoTab. 1) y La Bastida (Totana) (Anexo-Tab. 2), yacimientos excavados por nuestro equipo (Lull et al. 2011, 2014, 2015a, 2015b, 2015c) (Fig. 1). Ambos cubren toda la diacronía argárica y cuentan con registros funerarios representativos y detallados. Todas las sepulturas datan de las fases 2 ( $c$ a. 2000-1750 cal ANE) y 3 (1750-1550 cal ANE) definidas en ambos yacimientos. $\mathrm{Su}$ adscripción cronológica ha combinado datos cronométricos (series de dataciones de C14, la mayoría realizadas a partir de muestras óseas humanas tomadas de tumbas) y observaciones estratigráficas.

Las dos colecciones difieren en varios aspectos. La Almoloya aporta 105 conjuntos funerarios intactos (77 individuales, 24 dobles y 4 cenotafios) ${ }^{6}$, mientras que el registro de La Bastida es problemático a pesar de ser, con 236 conjuntos $^{7}$ uno de los más nutridos de la

${ }^{6}$ Las 105 tumbas proceden de nuestras excavaciones entre 2013 y 2016. Hemos prescindido de la información dispersa procedente de una cuarentena de tumbas expoliadas en la segunda mitad del siglo XX, cuyos restos hemos documentado. La excavación de 1944 no menciona restos faunísticos (Cuadrado Díaz 1945a, 1945b; Cierva y Cuadrado Díaz 1945).

Esta cifra totaliza las sepulturas halladas por R. Inchaurrandieta (en 1869), L. Siret y P. Flores (en 1886), el Seminario de Historia Primitiva del Hombre (1944-1950, Universidad Central, Madrid) y el Proyecto Bastida (2009-2013). Las intervenciones de los siglos XIX y XX se repasan en Lull et al. (2015a). arqueología argárica, tan solo superado por El Argar y El Oficio. El principal inconveniente se deriva de la desigual calidad de su documentación, ya que la mayoría de las tumbas fueron halladas en diversas excavaciones entre 1869 y 1950. En estas condiciones, la investigación se basará en las sepulturas excavadas por nuestro equipo entre 2009 y 2013, así como en cierto número de restos de fauna descubiertos en campañas previas, gracias al estudio directo de los mismos y de documentos gráficos y textuales de la época (Andúgar 2015: 1401-1469) ${ }^{8}$. Sin embargo, dado que solo las tumbas excavadas recientemente conforman una muestra completa formada por casos con y sin fauna y, por tanto, apta para un análisis comparativo interno, la mayor parte del trabajo girará en torno a esta, compuesta por 54 tumbas intactas ( 37 individuales, 9 dobles y 8 cenotafios); es decir, poco más de la mitad que la muestra de La Almoloya (54 frente a 105). Señalamos que, en La Bastida, el análisis de la fauna en conjuntos funerarios se beneficiará de los resultados de la investigación zooarqueológica de los niveles habitacionales (Andúgar 2016).

La relevancia cualitativa y cuantitativa de los registros de La Almoloya y La Bastida queda de manifiesto si tenemos en cuenta que, entre los dos, aportan 100 conjuntos funerarios con restos faunísticos. A título comparativo, la investigación más completa sobre el tema (Aranda y Montón 2011, 2016) se realizó sobre los datos de 57 sepulturas correspondientes a 9 yacimientos, entre los cuales el que más aportaba lo hacía con 22 casos (Fuente Álamo). Ahora bien, la importancia de La Almoloya y La Bastida no se mide solo en términos cuantitativos, sino porque permiten comparar conjuntos de tumbas con y sin fauna, de forma que ofrecen la posibilidad de detectar regularidades inadvertidas hasta ahora.

Las categorías empleadas para analizar la información zooarqueológica9 son "parte" y "porción". "Parte" es un término estrictamente anatómico $\mathrm{y}$, en este estudio, todas corresponden a extremidades. Las extremidades constan de cuatro partes: cintura, estilopodio, zigopodio y autopodio (Anexo-Fig. 1). Cada parte puede estar formada por un hueso, como fémur y húmero

\footnotetext{
${ }^{8}$ Hace años se publicó un estudio sobre los restos de fauna recuperados en las tumbas excavadas por el Seminario de Historia Primitiva del Hombre en la década de 1940 (Cereijo 1992). Sin embargo, la abundancia y variedad taxonómica de los restos sugieren que el estudio mezcló ofrendas y restos incorporados al relleno de las sepulturas por procesos tafonómicos. Al no haberse publicado la anatomía detallada del material óseo, la información contenida en este estudio carece de utilidad para nuestros propósitos.

${ }^{9}$ Las metodologías para la determinación anatómica y taxonómica de los restos faunísticos, así como las categorías y términos para designarlos se recogen en el Anexo.
} 


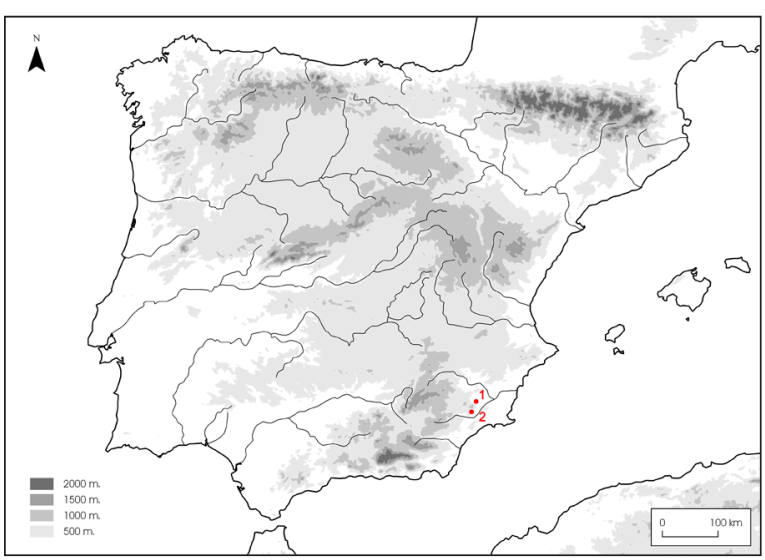

Fig. 1. Localización de los yacimientos de La Almoloya (1) y La Bastida (2).

(estilopodio) o por más de uno en conexión anatómica, como radio, ulna y carpos, o tibia, fíbula y tarsos (zigopodio). En cambio, "porción" remite a una selección social: la unidad mínima de asignación faunística. Si bien hay casos en que "porción" es igual a "parte", no sucede lo mismo cuando la porción incluye al menos dos partes en conexión anatómica, como por ejemplo tibia y tarsos (calcáneo, astrágalo, centrotarsal y maleolar $)^{10}$. La distinción es relevante, ya que una misma extremidad puede haber dado lugar a dos porciones si se depositaron partes anatómicas inconexas que ingresaron en la tumba por separado (p. ej., escápula por un lado, y radio y ulna por otro). Es decir, dos partes de una misma pata que no están articuladas en la anatomía del animal se contabilizan como dos porciones. A su vez, cuando en una sepultura se documentan al menos dos porciones, cabe la posibilidad de que correspondan a más de un animal. Por consiguiente, "parte", "porción" y "extremidad de un individuo" constituirán las categorías pertinentes para nuestro análisis.

Los restos de fauna en el interior de las sepulturas se han localizado en siete sectores que toman como referencia la típica posición de los cuerpos, esto es, extremidades inferiores flexionadas y lateralizadas respecto a un tronco que yacía en decúbito lateral o en supino (Anexo-Fig. 2). El análisis espacial también ha considerado la distancia de los restos faunísticos respecto a recipientes cerámicos, si los hubiere.

\footnotetext{
${ }^{10}$ Algunas porciones formadas por varios huesos articulados fueron documentadas in situ durante las excavaciones. Sin embargo, a menudo las alteraciones postdeposicionales habían modificado su disposición original. No se han registrado marcas de descarnado. Ello sugiere que, cuando fueron depositadas, mantenían tejidos blandos como indican los casos que habían conservado su posición primaria.
}

La clasificación de los ajuares funerarios según su valor social ha seguido los criterios establecidos por Lull y Estévez (1986), con un matiz en la categoría 3. En este caso, las tumbas con un único útil metálico, punzón o puñal, ocupan una categoría a caballo entre la 3 y la $4(3 / 4)$.

\section{ANÁLISIS (I): LA PRESENCIA DE FAUNA EN AJUARES FUNERARIOS DE LA ALMOLOYA Y LA BASTIDA}

El análisis seguirá dos vías. La primera estudiará la relación entre presencia y ausencia de fauna, con el fin de descubrir si esta era un complemento regular de ciertos elementos o atributos o, por el contrario, bajo qué circunstancias quedaba excluida. La segunda considerará únicamente las tumbas con restos faunísticos para explorar, por un lado, las características taxonómicas y anatómicas de las porciones depositadas y, por otro, las eventuales relaciones entre estas y otros elementos. Cotejaremos simultáneamente los datos de La Almoloya y La Bastida en los cinco ámbitos funerarios más relevantes: tipo de enterramiento, cronología, edad, sexo y clase social de los individuos inhumados.

\subsection{Tipo de enterramiento y restos faunísticos}

La frecuencia de conjuntos funerarios con alguna porción de fauna varía ligeramente: en La Almoloya ronda el $55 \%$, mientras que en La Bastida alcanza el $46 \%$ (Anexo-Tab. 3). En cambio, los resultados por tipo de enterramiento son semejantes: mayoría de tumbas individuales sin fauna, mayoría de tumbas dobles con fauna y proporciones similares en cenotafios. Las diferencias entre yacimientos parecen deberse a la mayor abundancia de sepulturas dobles con fauna en La Almoloya $(\mathrm{N}=21)$, una clase de conjuntos cuya naturaleza duplica, en teoría, la probabilidad de contener ofrendas. La mayor presencia de fauna en tumbas dobles es estadísticamente significativa en La Almolo$\mathrm{ya}^{11}$, pero no en La Bastida ${ }^{12}$. En estas circunstancias, si bien el porcentaje de tumbas dobles $(22,8 \%$ en La Almoloya; $16,6 \%$ en La Bastida) no es significativamente distinto entre ambos yacimientos ${ }^{13}$, la abundancia de tumbas dobles con fauna en La Almoloya ( $\mathrm{N}=21$, por 9 en La Bastida) inclina la balanza hacia la presencia de fauna en los conjuntos funerarios del primero.

\footnotetext{
${ }^{11} \chi^{2}$ : 13,094; g.1.: $1 ; p=0,0002$. Solo tres de las 24 tumbas dobles no incluían fauna en su ajuar.

${ }_{12}^{2} \chi^{2}: 2,7556$; g.1.: $1 ; p=0,096916$; test exacto de Fischer: $p=$ 0,13743 .

${ }^{13} \chi^{2}$ : 0,83089; g.1.: $1 ; p=0,36202$.
} 
Retengamos que, aun así, las diferencias entre conjuntos funerarios con o sin fauna son ligeras en términos generales. De hecho, si considerásemos las dos colecciones como una sola, se daría un virtual empate: 83 casos con fauna y 76 sin ella. A continuación, trataremos de identificar qué factores influyen o determinan la presencia de fauna, empezando por un factor genérico, la dimensión temporal.

\subsection{Cronología y restos faunísticos}

En las tumbas de La Almoloya y de La Bastida se depositaron porciones faunísticas desde las primeras manifestaciones funerarias a comienzos de la Fase 2 y hasta el final de sus ocupaciones a mediados del siglo XVI cal ANE. Ahora bien, las proporciones entre tumbas con y sin fauna variaron a lo largo del tiempo (Anexo-Tab. 4): en la Fase 2 más del $80 \%$ de las sepulturas de La Almoloya y del 75 \% de La Bastida incluían fauna, mientras que en la Fase 3 estos porcentajes se redujeron de forma drástica (hasta poco más de la tercera parte del total) y estadísticamente significativa ${ }^{14}$. Ello revela una tendencia consistente, ya que ambos yacimientos comparten valores porcentuales similares.

\subsection{Edad, sexo y clase social}

La fauna, en tanto elemento de ajuar, podría estar sujeta a los condicionantes por razón de sexo, edad y clase social en los conjuntos funerarios argáricos (Siret y Siret 1887; Lull y Estévez 1986; Lull et al. 2005).

\subsubsection{Edad}

La edad al morir de los sujetos en tumbas individuales, con y sin fauna, ofrece frecuencias muy dispares, diríase que opuestas, entre infantiles y personas de mayor edad (Anexo-Tab. 5). Así, mientras que solo el $9 \%$ (La Bastida) y el $20 \%$ (La Almoloya) de las tumbas infantiles contenían fauna, los porcentajes alcanzan el $80 \%$ (La Bastida) y el $66 \%$ (La Almoloya) cuando se consideran las de adolescentes y sujetos adultos y ancianos. Las diferencias en cada colección son estadísticamente significativas ${ }^{15}$. Así pues, la mayoría de las tumbas sin fauna corresponden a infantiles $y$, a la inversa, la fauna en ajuares funerarios se asocia significativamente a individuos que habían superado la

\footnotetext{
${ }^{14}$ La Almoloya: $\chi^{2}$ : 26,482; g.1.: $1 ; p=0,0001$; La Bastida: test exacto de Fisher: $p=0,008$.

${ }^{15}$ La Almoloya: $\chi^{2}$ : 16,769; g.1.: $1 ; p=0,00004$; La Bastida: test exacto de Fisher: $p=0,00001$.
}

infancia. Si incrementamos el detalle, ninguna criatura menor de 18 meses mereció ser enterrada con fauna. Aun así, las frecuencias por yacimiento revelan diferencias interesantes, ya que en La Bastida las sepulturas infantiles con fauna eran de Infans I (entre 18 y 30 meses), mientras que en La Almoloya eran de Infans II (mayores de 5-6 años, excepto una criatura de 3).

La introducción de la variable cronológica permite apreciar nuevos detalles. En La Almoloya ningún Infans I recibió ofrendas de fauna (3 datados en la Fase 2 y 22 en la 3). En cambio, 6 de los 7 Infans II de la Fase 2 tenían fauna asociada, invirtiéndose la tendencia en la Fase 3, con solo un caso sobre tres. El bajo número de Infans II en la Fase 3 impide enunciar una tendencia a la baja de la representación de la fauna con el paso del tiempo, pero la consideración de la muestra de personas adultas ${ }^{16}$ en La Almoloya revela una tendencia interesante (Anexo-Tab. 6), ya que la disminución observada en la Fase 3 resulta estadísticamente significativa ${ }^{17}$. Por tanto, estos resultados abren la posibilidad de que el derecho a recibir alguna porción de fauna se restringiese con el tiempo en La Almoloya. En La Bastida, el bajo número de efectivos impide ser concluyentes, aunque los datos disponibles mantienen una tónica de continuidad.

En resumen, el incremento de Infans I en la Fase 3 parece ser el principal responsable del descenso relativo de tumbas con fauna en esta fase, ya que solo excepcionalmente (La Bastida) algunos individuos menores de tres años merecieron estas ofrendas ${ }^{18}$. El aumento acusado de individuos de muy corta edad en el ritual funerario intramuros durante los dos últimos siglos de El Argar debió tener una motivación ideológica, aunque al parecer no cambió la dotación de ajuar faunístico respecto a la Fase 2. La pérdida de derechos de una parte de la población adulta pudo contribuir también, al menos en La Almoloya y a título de hipótesis, en la reducción de las tumbas con fauna en la Fase 3.

\subsubsection{Sexo}

En las tumbas individuales de La Almoloya ${ }^{19}$, la fauna no se asocia significativamente a sujetos de sexo

\footnotetext{
${ }^{16}$ Incluimos el único individuo infantil, datado en la Fase 3 de La Almoloya y cuyo ajuar carecía de porciones de fauna.

${ }_{17} \chi^{2}$ : 4,7727; g.1.: $1 ; p=0,028914$; test exacto de Fisher: $p=$ 0,048776

${ }_{18} \mathrm{La}$ excepcionalidad de la asociación de ofrendas de fauna a individuos menores de tres años se constata también en Fuente Álamo, donde solo las tumbas 84 (infantil de 0-3 meses) y 87 (2-3 años) manifiestan dicha asociación (Kunter 2000, 2004; Liesau y Schubart 2004).

19 Además de las determinaciones osteológicas para individuos juveniles y adultos, se incluyen aquí por primera vez las identificaciones mediante análisis de ADN en individuos infantiles.
} 
masculino o femenino ${ }^{20}$ (Anexo-Tab. 7). En La Bastida, pese a que el bajo número de efectivos dificulta un análisis fiable, tampoco se registra ninguna asociación significativa, aunque vale la pena señalar que los únicos tres adultos sin fauna eran mujeres y que todos los varones (cinco) tenían.

El análisis de la variable sexual tampoco revela diferencias diacrónicas significativas. En la Fase 2 de La Almoloya (Anexo-Tab. 8) una amplia mayoría de mujeres y hombres mereció ofrendas faunísticas. En la Fase 3 la mayoría de los ajuares femeninos siguieron incluyendo fauna, aunque en una proporción más moderada ( 8 a 6 ), mientras que entre los hombres pasaron a ser mayoría los inhumados sin fauna ( 2 a 4 ). Así pues, la tendencia ya apuntada hacia la reducción de ofrendas faunísticas en la Fase 3 se hizo a expensas de ambos sexos, aunque afectó más a los hombres en términos relativos. En cualquier caso, ello refuerza la idea de que el sexo biológico no condicionaba por sí solo el derecho a merecer ofrendas faunísticas. El bajo número de efectivos en La Bastida condiciona el análisis. Cabe señalar que las frecuencias absolutas de tumbas con fauna son similares para hombres y mujeres en cada fase, aunque el hecho de que todas las tumbas masculinas incluyan fauna rompe la tónica de igualdad entre sexos.

\subsubsection{Clase social ${ }^{21}$}

La relación entre la dimensión socioeconómica y las ofrendas faunísticas se ha dilucidado restringiendo el análisis a las tumbas individuales de adultos (Anexo-Tab. 9), es decir, a sujetos con una posición social plenamente reconocida. En La Almoloya, pese a que la fauna es relativamente más frecuente en los ajuares de las categorías intermedia y alta, las diferencias respecto a los de categorías inferiores no resultan significativas ${ }^{22}$. En La Bastida hemos maximizado el bajo número de tumbas individuales añadiendo aquellas dobles en las que al menos uno de los sujetos no hubiese fallecido en edad infantil. Los efectivos siguen siendo escasos y, en cualquier caso, tampoco muestran dife-

\footnotetext{
${ }^{20} \chi^{2}: 0,22281 ;$ g.1.: $1 ; p=0,63691$

21 A fin de determinar posibles relaciones en los datos y dadas las peculiaridades cuantitativas de la muestra, agrupamos los valores de las categorías 1-3 (denotadoras de mayor riqueza) y, por otro lado, los de las 3/4, 4 y 5 . Sobre estos dos grupos se realizó el análisis comparativo. Puntualizamos que la presencia de fauna en solitario en una tumba no desacredita su clasificación en la categoría 5 de Lull y Estévez (1986). Aquel análisis estadístico no incluyó las ofrendas faunísticas debido a los problemas de registro que afectaban a los restos faunísticos en excavaciones antiguas.

${ }^{22} \chi^{2}: 1,1832$; g.1.: $1 ; p=0,27671$; test exacto de Fisher: $p=0,39303$.
}

rencias significativas ${ }^{23}$. Aun así, es interesante anotar que la presencia de fauna es más frecuente en tumbas de categorías pobres (doce sobre trece) que entre las más ricas (cinco entre nueve).

La distribución cronológica según el valor social de los ajuares tampoco revela diferencias significativas (Anexo-Tab. 10). Pese a ello, la lectura de los valores porcentuales sugiere un descenso en la presencia de fauna en la Fase 3 entre los ajuares más pobres. Así, durante la Fase 2 de La Almoloya solo 4 de las 17 tumbas con ajuares pobres carecían de fauna, mientras que en la Fase 3 se duplicaron: 8 entre 17. Puede ser revelador que, pese al escaso número de efectivos de La Bastida, casi todas las tumbas pobres de la Fase 2 contaban con alguna porción de fauna ( 7 de 8 ) pero, en la Fase 3, solo una de las tres sepulturas.

Hemos dejado para el final el tratamiento de las tumbas dobles y los cenotafios. En La Almoloya las sepulturas dobles son más frecuentes que en La Bastida y muchas de ellas contenían fauna (Anexo-Tab. 3). Las 15 tumbas de la Fase 2 cuentan con esta clase de ofrendas, así como 6 de las 9 de la Fase 3; significativamente, las tres excepciones se asocian a casos con uno o dos infantiles. En La Bastida, las tres tumbas de la Fase 2 contenían fauna. En cambio, en la Fase 3, tres sí $\mathrm{y}$ tres no, sin que parezca haber influido en ello factores como la edad de fallecimiento o la riqueza del ajuar. Solo aproximadamente la mitad de las tumbas dobles de adultos duplican la ofrenda faunística cuando sería de esperar una proporción mayor, acorde con su abundancia en tumbas individuales de sujetos adultos. Esta circunstancia plantea de nuevo la remoción de elementos de ajuar con ocasión del segundo sepelio.

Los cenotafios suponen menos del $4 \%$ de los conjuntos funerarios de La Almoloya, pero casi el $15 \%$ en La Bastida. Estas frecuencias tan distintas no afectan a las restantes variables, que respetan una sorprendente uniformidad en ambos yacimientos. Todos los casos datan de la Fase 3, se asocian a ajuares escasos (categorías $3 / 4$ y, sobre todo, 4 y 5) y muestran proporciones similares entre presencia y ausencia de restos de fauna.

\section{ANÁLISIS (II): LAS OFRENDAS FAUNÍSTICAS EN AJUARES FUNERARIOS DE LA ALMOLOYA Y LA BASTIDA}

La base de la investigación sobre posibles criterios en la asignación de porciones de fauna es una colección formada por 100 conjuntos funerarios $(58 \mathrm{de} \mathrm{La}$ Almoloya y 42 de La Bastida ${ }^{24}$. Las porciones corres-

\footnotetext{
23 Test exacto de Fischer: $p=0,11586$.

24 Estos últimos corresponden a 25 tumbas registradas en nuestras excavaciones entre 2009 y 2013 , y a 17 procedentes de las intervenciones
} 
ponden a 121 animales distintos (73 de La Almoloya y 48 de La Bastida). En La Almoloya, la diferencia entre 58 tumbas con fauna y 73 individuos se debe a que, en 15 sepulturas, se hallaron restos pertenecientes a dos animales ${ }^{25}$. Los 42 conjuntos de La Bastida han proporcionado evidencias de 48 individuos ${ }^{26}$.

\subsection{Frecuencia de partes anatómicas y tafonomía}

Las ofrendas faunísticas siempre corresponden a extremidades. En La Almoloya, lo más habitual es hallar elementos óseos de una $(23,28 \%)$, dos $(45,20 \%)$ o tres $(26,02 \%)$ de las cuatro partes anatómicas que las componen (Anexo-Tab. 11). En La Bastida el panorama varía, dominado ampliamente por dos posibilidades: una parte $(30,4 \%)$ o dos $(67,4 \%)$. La porción equivalente a una pata entera, compuesta por huesos conectados de las cuatro partes anatómicas, no se ha documentado en La Bastida y solo en cuatro de los 73 individuos de La Almoloya $(5,47 \%)^{27}$. También cabe señalar que, en general, los carpos y los tarsos son los únicos representantes del autopodio. Falanges y metápodos debieron haber sido desechados al desollar el animal: se han observado marcas de corte resultado de esta acción en cuatro tumbas de La Almoloya.

Todo análisis sobre la deposición de elementos faunísticos requiere, en primer lugar, detectar posibles sesgos tafonómicos derivados de una eventual preservación diferencial. La edad de sacrificio es uno de los factores a priori más influyentes, ya que los individuos infantiles, al no haber concluido la osificación, están más expuestos a quedar infrarrepresentados. Esta posibilidad se ha evaluado mediante un análisis de contingencia para cada grupo de frecuencias de partes anatómicas representadas en cada tumba, según la edad de sacrificio (infantil, juvenil y adulta) (Anexo-Tab. 11). En La Almoloya se observan diferencias significativas $^{28}$, motivadas por las elevadas frecuencias de animales infantiles en las categorías de dos y cuatro

de L. Siret y P. Flores en 1886 y del equipo del Seminario de Historia Primitiva del Hombre en 1944, 1945 y 1950.

${ }^{25}$ Como la mayoría de estas 15 tumbas son dobles $(\mathrm{N}=11)$, la presencia de porciones de dos animales puede deberse a que cada cadáver mereció partes de uno, sin que los restos faunísticos del primer funeral fueran retirados con ocasión del segundo. Como hemos señalado, a veces se ha deducido la extracción de elementos del ajuar del primer individuo inhumado, durante el funeral del segundo en este tipo de sepulturas. Solo cuatro tumbas individuales tienen restos de dos animales.

${ }^{26}$ Algo más de la mitad de las porciones corresponde a tumbas individuales. La frecuencia de tumbas dobles supera ligeramente el $20 \%$. Sorprende en La Bastida la abundancia relativa de cenotafios.

${ }^{27}$ Curiosamente, cuando porción y parte son lo mismo, siempre se acompañan de la porción de otro animal.

${ }^{28} \chi^{2}$ : 14,$601 ;$ g.1.: $1 ; p=0,023598$; test exacto de Fisher: $p=$ 0,030122 . partes por tumba. En La Bastida no se alcanza el nivel de significación y las cifras de porciones de animales infantiles no desentonan respecto a las de los sacrificados a otras edades. En consecuencia, la destacada representación de individuos inmaduros sugiere que la influencia de los factores tafonómicos fue escasa o nula y además, en el caso de La Almoloya, alerta sobre una preferencia que revisaremos más adelante.

\subsection{Representación taxonómica}

En La Almoloya hay un predominio neto de ovejas y cabras ( $90 \%$, Anexo-Tab. 12). El ganado ovino, por sí solo, supera el $50 \%$ y es más del doble que el caprino. De hecho, el porcentaje de Ovis aries se aproximaría a los dos tercios del total si le asignásemos la parte proporcional esperable del grupo indiferenciable de ovejas/cabras. En el extremo opuesto, con valores muy bajos en torno al $5 \%$, hallamos suidos y bovinos.

En La Bastida, las tres cuartas partes de las ofrendas correspondían a ovejas y cabras, aunque aquí en igual proporción. En los conjuntos habitacionales de La Bastida, el número y el peso de los restos de ovejas y cabras es parecido a lo largo del tiempo, con un leve predominio de Ovis aries (Andúgar 2016: 315, tab. 11.3). La frecuencia de Bos taurus, casi el $20 \%$, supera notablemente la de La Almoloya, mientras que la de Sus domesticus ocupa el último lugar, ligeramente por debajo del $10 \%{ }^{29}$.

El estudio de la fauna en conjuntos habitacionales de La Bastida permite entender algunos pormenores sobre la selección de especies en las ofrendas funerarias. Según el parámetro "número mínimo de individuos" (NMI) (Anexo-Tab. 13), la suma de ovejas y cabras alcanza los valores más altos, tal y como sucedía en el registro funerario. Sin embargo, Ovis aries duplica a Capra hircus, lo cual se ajusta a la tendencia funeraria de La Almoloya, pero no así a la de La Bastida, donde ovejas y cabras presentan valores iguales ${ }^{30}$. Las diferencias entre ovejas y cabras en conjuntos habitacionales y funerarios de La Bastida no resultan significa$\operatorname{tivas}^{31}$, pero pueden indicar cierta preferencia hacia el

\footnotetext{
${ }^{29}$ Además de lo ya señalado respecto a ovejas y cabras, las cifras globales del parámetro "número de restos" para la fauna doméstica en La Bastida respetan el mismo orden que acabamos de presentar (Andúgar 2016: 313). De la lista de taxones en conjuntos habitacionales, tan solo faltan en el ámbito funerario los équidos y cánidos, especies no criadas específicamente para el aprovechamiento cárnico y poco frecuentes en el registro faunístico.

${ }^{30}$ No se ha considerado la categoría Ovis aries/Capra hircus, dado que podría sobrerrepresentar los valores de este parámetro. Al no hacerlo somos conscientes que también podría producirse el efecto contrario, es decir, la infrarrepresentación de estas especies. Por tanto, las posibles tendencias serán consideradas solo a título orientativo.

${ }^{31} \chi^{2}: 1,7343 ;$ g.1.: $1 ; p=0,18786$.
} 
ganado caprino en el ritual funerario. Es interesante en este sentido que el ganado vacuno y el porcino abundan más que el caprino en los contextos habitacionales de La Bastida, mientras que la relación es inversa en el ámbito funerario. Ello también apunta a una preferencia por el ganado caprino o, tal vez mejor, planteándolo a la inversa, a una renuencia al sacrificio de ovinos, bovinos y suidos con ocasión del ritual funerario. El resultado es que aquí la representación de caprinos superó su importancia en la subsistencia cotidiana. Las razones pudieron ser de orden diverso, tal vez de rentabilidad económica en el caso del ganado vacuno y ovino, o de otro orden respecto al porcino.

En resumen, las frecuencias de fauna como elemento de ajuar funerario en La Almoloya y La Bastida se asemejan en general a las de la fauna doméstica consumida en La Bastida en lo que respecta al predominio de ovejas y cabras. No obstante, al menos en La Bastida se identifican filtros económicos o ideológicos que evitan que el registro funerario dé una imagen fidedigna de las prácticas cotidianas de sacrificio. Sin alejarnos de la aplicación de filtros sociales, las evidencias de $\mathrm{La}$ Almoloya y La Bastida indican sin ninguna duda que la fauna salvaje fue excluida del ritual funerario ${ }^{32}$, pese a su relativa importancia en la dieta. Tal vez su condición de recurso eventual condicionado por el éxito de la actividad cinegética la hacía poco apropiada para la asignación funeraria, en comparación con la disponibilidad, posiblemente más inmediata y segura, de los animales domésticos.

En términos diacrónicos, en La Almoloya no se aprecian diferencias estadísticamente significativas entre las fases 2 y 3 a propósito de Ovis aries y $\mathrm{Ca}$ pra hircus, las únicas especies con una representación sustancial (Anexo-Tab. 14) ${ }^{33}$. Aun así, destacamos una drástica disminución de cabras en la Fase 3 que las sitúan a nivel testimonial incluso por debajo de Bos taurus y Sus domesticus. En La Bastida, el escaso número de efectivos con asignación cronológica segura dificulta extraer conclusiones. Sí cabe señalar que todas las especies se hallan representadas a lo largo de la diacronía, sin que se observen variaciones sustanciales.

\subsection{Edades de sacrificio y partes anatómicas seleccionadas}

Aproximadamente la mitad de los individuos en $\mathrm{La}$ Almoloya eran infantiles, seguidos con casi un $30 \%$ por juveniles/subadultos y solo una quinta parte de

\footnotetext{
32 En otros yacimientos argáricos la presencia de fauna salvaje como ofrenda funeraria es, a lo sumo, esporádica (Liesau y Schubart 2004; Aranda 2016).

33 Test exacto de Fisher: $p=0,29864$.
}

adultos (Anexo-Tab. 15). Las frecuencias de las especies mayoritarias, ovejas y cabras, son semejantes. En cambio, las minoritarias muestran tendencias opuestas: los ejemplares de vacuno eran adultos y los suidos de muy corta edad. En conjunto, se observa un equilibrio entre el sacrificio de animales de edad temprana y de los que habían alcanzado su óptimo cárnico a edades juvenil y adulta. En La Bastida, al contrario, predominan los animales sacrificados en su óptimo cárnico y la selección de infantiles ronda la tercera parte del total.

En La Almoloya, además de la tendencia a depositar porciones de ovejas y cabras infantiles o, en general, de edad subadulta, se identifica un patrón relativo a la parte anatómica. Junto a la exclusividad absoluta de las extremidades hay una preferencia muy acusada por las delanteras: solo 3 de 73 son cuartos traseros. Además, la mayoría son extremidades del lado izquierdo (44 casos, 60,3\% de la muestra) (Fig. 2). La aplicación de estos dos criterios de selección (extremidad delantera y lateralidad izquierda) no incluyó diferencias significativas entre especies. Esta regularidad parece indicar una dimensión simbólica característica de $\mathrm{La}$ Almoloya.

La Bastida ofrece una situación antagónica, ya que muestra una preferencia marcada por las extremidades posteriores (42 casos de 48 , casi el $90 \%{ }^{34}$ ) y, además, la lateralidad mayoritaria es la derecha $(25$ casos del lado derecho $-55,6 \%$-, frente a 20 casos del izquierdo $-44,4 \%$-) (Fig. 2). De nuevo, la selección predominante (extremidades posteriores del lado derecho) se aplicó a todas las especies sin variaciones estadísticamente significativas.

La frecuencia de partes anatómicas en La Almoloya indica que el zigopodio anterior (antebrazo) es la más representada con diferencia, seguida por la cintura escapular y los carpos (Anexo-Tab. 16). La presencia de marcas de corte en la articulación del codo atestigua el proceso de descuartizamiento y la subsiguiente selección de una o dos porciones como ofrenda. El antebrazo se presenta en solitario o, más comúnmente, asociado a la escápula y/o a restos del autopodio anterior. La escápula solo aparece aislada una vez. Lo más frecuente es su asociación al menos con otra parte anatómica, aunque nunca solamente con autopodio en combinaciones dobles. El autopodio nunca se documenta en solitario.

Las bajas frecuencias de húmero ${ }^{35}$ y fémur revisten especial interés para el tema que nos ocupa, porque son

\footnotetext{
34 Además, las pocas veces en que se registran extremidades delanteras se asocian a otras peculiaridades contextuales: las dos porciones de oveja coinciden en ser ajuar externo y aparecen en dos de las escasas tumbas infantiles con fauna.

${ }^{35}$ E. y L. Siret (1887: 406) ya repararon en ella al referirse a los huesos de caprinos hallados en las sepulturas de El Argar.
} 

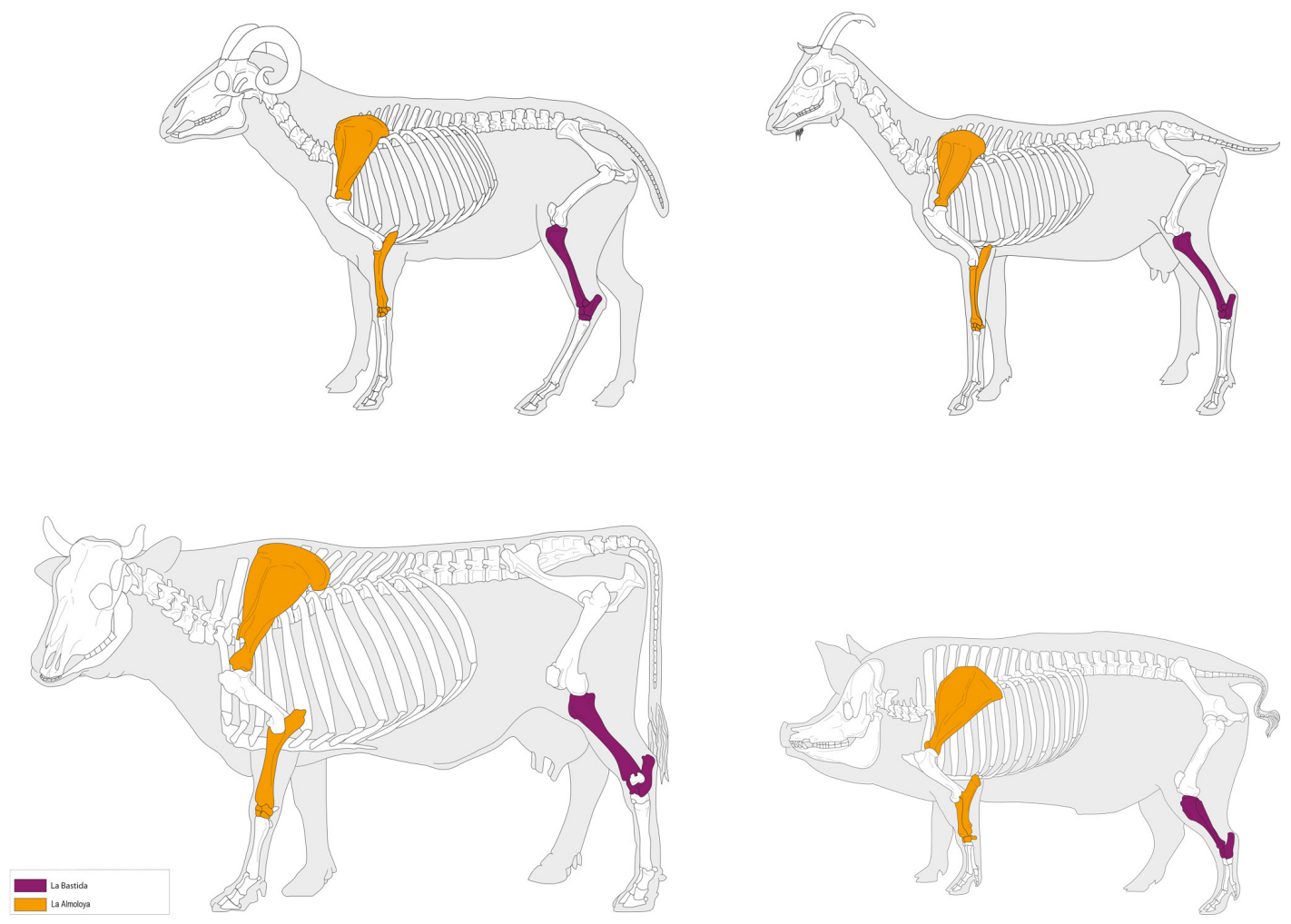

Fig. 2. Representación sintética de las partes anatómicas mejor representadas, depositadas en las tumbas argáricas de los asentamientos de La Almoloya y La Bastida (Murcia) (beige: La Almoloya; morado: La Bastida). De izquierda a derecha y de arriba abajo Ovis aries, Capra hircus, Bos taurus y Sus domesticus. En color en la edición electrónica.

los huesos de las extremidades asociados a una mayor masa cárnica y contenido en médula. Sorprende su escasez si, como se defiende desde las interpretaciones en clave de "comensalidad", uno de los propósitos rituales fue hacer partícipe del banquete funerario a la persona fallecida (Aranda y Esquivel 2007: 115; Aranda 2008: 117). La cantidad de carne asociada a la ulna y al radio de ovejas y cabras es escasa, aunque ligeramente mayor en la escápula ${ }^{36}$. A la luz de estos datos la hipotética participación de la persona difunta en el banquete sería, podríamos decir, más simbólica que nunca.

La ofrenda de una o varias partes de una misma extremidad indica su colocación una vez completado el proceso de despiece, cuando las porciones se hallaban listas para proseguir el proceso culinario pero sin cocinar, ya que faltan marcas de termoalteración. Ello añade otra duda a su consideración como "alimento". Los restos hallados en conjuntos habitacionales de La Bastida muestran con frecuencia alteraciones por ha-

\footnotetext{
${ }^{36}$ El escaso acompañamiento de carne y grasa en los restos óseos documentados también ha sido puesto de relieve en el estudio específico de Fuente Álamo (Liesau y Schubart 2004: 103).
}

ber sido asados, pero los depositados en tumbas nunca parecen haber estado expuestos a una fuente de calor. Es cierto, no obstante, que la ausencia de indicios de termoalteración no descarta el cocinado, ya que se ha comprobado que el hervido, incluso durante varias horas, puede no dejar ningún indicio físico o químico en el material óseo (Roberts et al. 2002: 485-493). Pese a esta incertidumbre, la falta de termoalteraciones por asado en los restos hallados en tumbas marca una diferencia cualitativa respecto a los procedentes del asentamiento, que impide dar por sentado su preparación como "alimento". Profundizaremos más sobre esta cuestión en el siguiente apartado.

En La Bastida se observa una preferencia muy acusada por las porciones distales posteriores. La suma de restos del zigopodio (tibia/fíbula) y tarsos supera el $80 \%$ del total. De hecho, la combinación de ambas porciones es la asociación más frecuente. Nuevamente, por tanto, las porciones depositadas no eran las de mayor masa cárnica asociada. En La Bastida solo se documentan tres muslos (fémures) sobre un total de 42 extremidades posteriores, así como dos húmeros de las anteriores. Además, cuando aparecen, son las úni- 
cas porciones de sus respectivas patas. En cambio, la mayor frecuencia corresponde a partes distales de las extremidades, que se caracterizan por un aporte cárnico muy escaso, aún menor en individuos de corta edad. En resumen, la selección anatómica en La Bastida obedeció a un claro patrón: porciones distales (zigopodio y autopodio) de extremidades posteriores. Las escasas excepciones a esta norma trasladan dicha selección a las extremidades anteriores.

La misma preferencia por los cuartos traseros expresada en La Bastida se ve en la mayoría de los yacimientos argáricos estudiados (Fuente Álamo, Cuesta del Negro, Lorca, Los Cipreses) ${ }^{37}$. En cambio, el patrón de La Almoloya muestra criterios de selección opuestos. Pudo ser seguido únicamente por la comunidad de Cerro de la Encina, aunque aquí predominan los restos de húmero mientras que en La Almoloya solo hay 10 entre 70 restos de cuartos delanteros.

\subsection{Alimento o símbolo}

Establecer si la población argárica conceptualizó como "alimento" las porciones de fauna en tumbas no es una cuestión cerrada tras observar que no suelen depositarse las que aportan más nutrientes. Pese a que la cantidad de carne amortizada fuese mínima, cabría argumentar que el proceder simbólico empleó una sinécdoque según la cual una parte, incluso ínfima, pudo igualmente aludir a una totalidad, ya fuese una ración de comida o un animal doméstico entendido como recurso alimenticio.

Con el fin de profundizar en esta dimensión simbólica, hemos explorado en primer lugar la relación entre la ubicación de los restos faunísticos y el individuo inhumado y, a continuación, con respecto a los recipientes cerámicos, ya que ambas dimensiones pueden arrojar luz sobre los vínculos simbólicos entre ofrenda faunística y "alimento". En ambos casos, la variable analizada es "porción".

\subsubsection{Vinculación espacial entre ofrenda e individuo}

En esta primera aproximación, la clave que reforzaría la idea de ofrenda alimentaria residiría en la colocación de porciones de fauna cerca de la cara o de la boca del individuo; es decir, la parte del cuerpo donde se

\footnotetext{
${ }^{37}$ Liesau y Schubart (2004), específicamente para Fuente Álamo; una perspectiva global en Aranda (2016: 22). El análisis preliminar de los restos faunísticos de El Argar y El Oficio conservados en la colección Siret (Museos Reales de Arte e Historia, Bruselas) marca la misma tendencia (estudio en curso).
}

realiza la ingesta. Esta ubicación corresponde al sector 2 de nuestra sistematización (Anexo-Fig. 2).

En La Almoloya, hay 32 tumbas individuales con fauna y sin alteraciones postdeposicionales relevantes, aptas para el análisis espacial. En cuatro de ellas había restos de dos animales. Por tanto, son 57 las porciones contabilizadas en las 32 sepulturas. En La Bastida, 12 sepulturas tienen 13 porciones faunísticas (Anexo-Tab. 17).

En La Almoloya, el sector 2 es el más representado con diferencia. Si consideramos conjuntamente los sectores 2 y 1 (en torno a la cabeza), el porcentaje alcanza casi el $60 \%$. Por el contrario, los sectores 6 (espalda) y 5 (pies/glúteos), los más alejados de la cabeza, sumados al sector 7 (exterior del contenedor funerario), apenas superan el $20 \%$. La prueba de bondad de ajuste confirma que la diferencia respecto a los valores esperados resulta estadísticamente significativa ${ }^{38}$. En consecuencia, este resultado sería compatible con la hipótesis de que, en La Almoloya, se consideraban las porciones de fauna como "alimento".

En La Bastida parece definirse una tendencia a colocar las porciones cerca de la espalda (sector 6) y a los pies/glúteos (sector 5) del cadáver. Los sectores más alejados de las partes del cuerpo implicadas en la ingesta alcanzan las tres cuartas partes del total sumando las porciones depositadas en el exterior del contenedor. Por tanto, el panorama es el opuesto al observado en La Almoloya ${ }^{39} \mathrm{y}$, la conclusión, también: en La Bastida la distribución de las porciones de fauna no parece avalar su consideración como "alimento".

\subsubsection{Vinculación espacial entre fauna y cerámica}

Los contenedores cerámicos fueron utilizados muy probablemente para la preparación y servicio de comida y bebida, por lo que una hipotética cercanía con los restos de fauna reforzaría su papel como ítems vinculados con la categoría "alimento".

El examen de la ubicación de porciones de fauna y recipientes cerámicos muestra una uniformidad en ambos yacimientos que diluye sus diferencias en la distribución de las porciones faunísticas respecto al cadáver. En La Almoloya, en el $80 \%$ de los 22 casos observados se verificó una clara proximidad, independiente del sector ocupado por ambas clases de ítems. Solo 3 de

\footnotetext{
${ }^{38} \chi^{2}: 9,7822 ;$ g.1.: $2 ; p=0,0075$

39 La prueba de bondad de ajuste revela diferencias significativas, en este caso favorables a la asociación entre fauna y los sectores más alejados de la cabeza $\left(\chi^{2}: 9,5 ;\right.$ g.1.: $\left.2 ; p=0,0086\right)$. Sin embargo, el bajo número de efectivos limita la fiabilidad de esta conclusión: solo disponemos de 12 tumbas individuales con datos precisos sobre la ubicación original de las ofrendas faunísticas (sectores 1-2: $n=2 ; 3-4: n=1 ; 5-6-7: n=9$ ).
} 
las 25 sepulturas individuales con Infans I (todas ellas sin fauna), incluyen una vasija, mientras que, entre los Infans II, su presencia es netamente minoritaria. Por tanto, la disposición de elementos relacionables con el consumo alimentario es casi nula entre la población de menor edad y, cuando se documenta a partir de los tres años, los restos faunísticos son los más frecuentes.

Las dos terceras partes de la población no infantil de La Almoloya, siempre teniendo en cuenta la inhumada en tumbas individuales, mereció algún recipiente cerámico $(\mathrm{N}=28$ frente a $\mathrm{N}=14)$, la mayoría de las veces acompañado también de fauna $(\mathrm{N}=20$ con fauna y cerámica frente a $\mathrm{N}=8$ solo con cerámica). Contenían fauna 8 de las 14 tumbas sin cerámica, de forma que solamente 6 personas que habían superado la infancia ${ }^{40}$ (la séptima parte de este colectivo con un solo juvenil) carecían de elementos relacionables con la alimentación, ya fuese cerámica y fauna combinadas o una u otra. En resumen, los elementos potencialmente vinculados con el consumo alimentario, fauna y cerámica, aumentan con la edad de fallecimiento hasta ser extraordinariamente frecuentes.

La proximidad entre restos óseos y recipientes cerámicos también parece verificarse en La Bastida. En este caso hemos incorporado las tumbas dobles con fauna, y la asociación entre fauna y cerámica casi se triplica (ocho vecindades estrechas frente a tres distanciamientos).

Como es posible que las porciones de fauna y vasijas expresen donaciones alimentarias, solo incluimos 3 tumbas con vasijas de las 20 sepulturas ocupadas en exclusiva por infantiles sin fauna. Por tanto, estas serían las únicas que pudieron incluir algún tipo de alimento. En dos fueron inhumados Infans II, mayores de seis años y, por ello, con posibilidad de haber disfrutado de ciertos derechos hereditarios (Lull et al. 2005) ${ }^{41}$. Solo hay un Infans II más en nuestra muestra y sin ajuar. Por tanto, en La Bastida solo se registra un caso, a todas luces excepcional, por haber sido enterrado con alimentos o bebidas tras fallecer a una edad muy temprana (12-14 meses). Las tendencias observadas en el acompañamiento cerámico de las tumbas infantiles se consolidan, si tenemos en cuenta que 4 de las 5 tumbas individuales y dobles con adultos y sin fauna contenían

\footnotetext{
${ }^{40}$ Las seis tumbas incluyen ajuares pobres o relativamente pobres (categorías 3/4, 4 y 5); cinco de ellas son mujeres.

${ }^{41}$ En la serie de tumbas con registro incompleto halladas en el siglo XX, la BAJ7 (tumba 7 de la campaña de F. Jordá, en 1950; véase Lull et al. 2015a) contenía un Infans II con un cuenco y fauna. Por tanto, de nuevo un infantil relativamente mayor. Además, llama la atención que las dos tumbas infantiles con fauna sean de las sepulturas más antiguas y con un tipo de enterramiento inusual en La Bastida. Puede ser interesante ver en ellas algunas de las primeras tumbas infantiles intramuros que contaron con un atributo funerario habitual (la deposición de fauna), atributo que no perduró posteriormente para la cohorte de edad más temprana. La única tumba infantil de época reciente con fauna y, además, una cerámica exterior, es BA65, una sepultura doble.
}

entre uno y dos recipientes cerámicos y solo una carecía por completo de ajuar ${ }^{42}$. Es decir, entre la población adulta era muy frecuente depositar cerámica.

En resumen, la inclusión en una tumba infantil de La Bastida de algún componente alimenticio, ya sea porción de fauna y/o recipiente, fue una práctica excepcional. La primera pudo haberse dado tan solo en los albores del ritual intramuros infantil, mientras que la de algún alimento o bebida en recipientes cerámicos pudo haberse reservado a ciertos Infans II con derechos heredados. En cambio, la ofrenda de porciones de fauna y/o alimentos/bebidas en contenedores de consumo $y$, a veces, de cocina o servicio, fue habitual entre la población adulta.

\subsection{Taxones faunísticos con respecto al sexo, edad y clase social de las personas inhumadas}

Abordar este abanico de relaciones requiere tomar en consideración, en primera instancia, solo las sepulturas individuales ${ }^{43}$. La exploración de la variable sexo en La Bastida afronta la escasez de determinaciones (ocho tumbas femeninas y cinco masculinas). En un análisis preliminar no se aprecian preferencias concretas; tampoco, si atendemos a la relación entre las variables sexo y lateralidad de la extremidad depositada, que muestra una casi total paridad entre mujeres ( 4 derechas y 4 izquierdas) y hombres (3 derechas y 2 izquierdas).

En La Almoloya la comparación entre las dos especies mayoritarias, Ovis aries y Capra hircus, y el sexo biológico de los humanos asociados (Anexo-Tab. 18) no revela ninguna asociación significativa ${ }^{44}$. Ahora bien, la variable sexo no es independiente de la lateralidad en la extremidad seleccionada, porque se manifiesta una asociación significativa entre hombres y porciones faunísticas del lado izquierdo ${ }^{45}$. De hecho, la asociación presenta visos de exclusividad, al no haberse documentado ni un solo varón con una porción faunística derecha (Anexo-Tab. 19). Los doce $\operatorname{casos}^{46}$ que apoyan esta afirmación datan de toda la diacronía y se refieren a ovejas y

\footnotetext{
42 Estas cuatro tumbas incluían al menos un recipiente pequeño, posiblemente de consumo. Dos de ellas, además, poseían una olla mediana, tal vez de cocina o servicio. Esta conclusión se refuerza al explorar la presencia de cerámica en las tumbas individuales y dobles con fauna (incluyendo 6 procedentes de excavaciones antiguas): en 19 de 24 (80\%) había entre uno y tres recipientes, y solo 5 (dos infantiles) carecían de cerámica. Cuando hay un único recipiente, es habitual que se trate de consumo y, cuando hay varios, al menos uno pudo ser de cocina o servicio.

${ }_{43}$ En las tumbas individuales con dos porciones de la misma especie, solo hemos contabilizado una unidad.

${ }^{44}$ Test exacto de Fisher: $p=0,67582$.

45 Test exacto de Fisher: $p=0,005$.

${ }^{46}$ Los niños de AY46, AY75 y AY95, recientemente identificados como de sexo masculino gracias a análisis de ADN, también fueron inhumados con sendas porciones faunísticas de lateralidad izquierda.
} 
cabras de todas las edades. Esta constatación tiene especial interés habida cuenta de la disposición mayoritaria de los hombres argáricos sobre el costado izquierdo, o en decúbito supino con las extremidades lateralizadas hacia la izquierda (Lull et al. 2016: 45 y tab. 4) ${ }^{47}$. Las mujeres yacían mayoritariamente sobre su costado derecho, o sobre la espalda con las piernas lateralizadas hacia la derecha, pero, en cambio, la lateralidad de las porciones faunísticas es indistinta.

No se aprecia ninguna otra preferencia por razón de sexo más allá de esta, lo cual coincide con las conclusiones de otros trabajos (Aranda 2016: 22). Tampoco hay diferencias significativas en la distribución de las dos especies mayoritarias entre tumbas masculinas y femeninas, que es más bien paritaria (Anexo-Tab. 18).

La relación entre restos faunísticos y edad de fallecimiento solo es abordable en La Almoloya, por la insuficiencia de efectivos en La Bastida. Como hemos señalado, la principal directriz en lo que respecta a la edad fue la exclusión de porciones de fauna para menores de 3 años. Para los Infans II, las porciones de ganado ovino o caprino nunca son de animales adultos ${ }^{48}$, una regularidad que el bajo número de casos impide confirmar si resulta significativa.

Finalmente, el análisis de la distribución de las categorías de ajuar en tumbas de individuos juveniles y adultos es poco elocuente, porque las frecuencias de algunas combinaciones son bajas o nulas. La situación no mejora lo suficiente incluyendo todas las tumbas de adultos, individuales o dobles ${ }^{49}$. Hemos agrupado en dos conjuntos las cinco categorías de referencia para maximizar los datos disponibles (Anexo-Tab. 20) ) $^{50}$. De nuevo, la escasez de bovinos y suidos limita el alcance de las conclusiones. Si los dejamos de lado y nos centramos en Ovis aries y Capra hircus, no se observan relaciones significativas ${ }^{51}$. Sin embargo, y pese a las limitaciones citadas, la distribución de valores en La Almoloya permite extraer conclusiones relevantes. La

\footnotetext{
${ }^{47}$ La deposición generalizada de varones sobre el costado izquierdo también ha sido advertida en otras regiones ibéricas y europeas, vinculada al fenómeno campaniforme.

${ }^{48}$ Aranda y Montón (2011: 143-144) señalan una asociación entre ovejas y cabras, y tumbas infantiles, también advertida en Fuente Álamo (Schubart 2012: 68)

49 Cuando en una tumba se recuperaron dos porciones de fauna, se contabilizan como entradas independientes. La razón es que nuestro propósito es determinar si hubo alguna relación entre especies y consideración social, no tanto entre la dotación faunística de ciertas tumbas y este mismo parámetro.

${ }_{50}$ Nos referimos siempre a las categorías de ajuar definidas por Lull y Estévez (1986) y complementadas en Lull et al. (2005). Recordemos que la presencia de un único útil metálico, en lugar del par normativo característico de la tercera categoría (hacha y puñal/cuchillo para hombres, punzón y puñal/cuchillo para mujeres), equivale a la categoría denominada aquí $3 / 4$.

${ }_{51} \chi^{2}: 0,55433$; g.1.: $1 ; p=0,45656$; test exacto de Fischer $p=$ 0,72713 .
}

primera es sorprendente: las categorías de ajuar 1 y 2 , vinculadas con la clase dominante, incluyen mayoritariamente porciones de ovejas o cabras, sobre todo de las primeras. Ello difiere de la tendencia enunciada en otros estudios (Liesau y Schubart 2004; Aranda 2016; Lull et al. 2017) y, como veremos, en La Bastida, que sostiene una estrecha correlación entre clase dominante y ganado bovino. En La Almoloya, Bos taurus, poco representado, se asocia más bien a la tercera categoría de ajuares y, solo en uno de los cuatro casos posibles, a la primera. Podríamos formularlo así: los restos de bovino se asocian a tumbas con ajuares de categorías intermedia y alta, pero lo contrario no es válido porque los ajuares de dichas categorías se asocian mayoritariamente a otras especies, sobre todo a ganado ovino. Otra conclusión en apoyo de la primera es que la misma clase de porciones de ganado ovino documentada en las tumbas de primera categoría también lo fue en las de las restantes categorías de ajuar, incluyendo aquellas donde la fauna es el único elemento. Por último, el ganado caprino, siempre en inferioridad respecto al ovino, presenta frecuencias constantes con la salvedad de su falta en ajuares de primera categoría. El bajo número de efectivos, no obstante, impide concluir que se trata de una relación de exclusión.

En La Bastida, la distribución de frecuencias absolutas indica que los ajuares con mayor valor social contaron con porciones de ovinos y bovinos. Así, las tres tumbas con ajuares de las categorías 1 y 2 poseen porciones de vacuno. Los ajuares de la categoría 3 merecieron casi siempre porciones de ovino, documentándose además una tumba con vacuno y el único caso de caprino en esta categoría. Como en La Almoloya, se adivina la exclusión del ganado caprino en las tumbas de la élite. En las categorías de ajuar más pobres se seleccionaron cabras, ovejas y cerdos, nunca ganado vacuno.

Así pues, en La Bastida no se observan preferencias en la selección de especies según el sexo y/o la edad de la persona fallecida. Los ajuares de la clase dirigente solían incluir porciones de ganado vacuno, aunque esta asociación no resultó exclusiva, ya que también hay Bos taurus en algún ajuar de categoría 3. Las restantes clases sociales optaron por ovejas, cabras y, en menor medida, cerdos. La tendencia apuntada en otros trabajos sobre la asociación entre individuos infantiles y ovejas y cabras $^{52}$ hallaría sentido si combinamos la escasez de tumbas infantiles de la clase dominante con una posible adquisición de elementos de ajuar por razones de edad, como ocurre entre los miembros de esta clase a propósito de alabardas, espadas y diademas.

Trab. Prehist., 78, N. ${ }^{\circ}$ 1, enero-junio 2021, pp. 104-120, ISSN: 0082-5638

https://doi.org/10.3989/tp.2021.12267 


\section{VALORACIÓN COMPARATIVA}

Tras analizar los registros de La Almoloya y La Bastida, es el momento de sintetizar el papel de la fauna en el ritual funerario (Anexo-Tab. 21). Pese a las diferencias cuantitativas en la composición de las dos muestras, las principales conclusiones son:

a) La asignación de porciones de fauna data de las primeras manifestaciones del ritual funerario intramuros, a inicios del II milenio cal ANE.

b) En una primera aproximación, las tumbas sin fauna son más frecuentes que las que la tienen. Este predominio se debe la abundancia de tumbas infantiles durante la fase argárica final, carentes de fauna salvo contadas excepciones (un Infans I en La Bastida y varios Infans II en La Almoloya).

c) La mayoría de los individuos adultos contaron con ofrendas faunísticas.

d) En términos diacrónicos, la población adulta de la Fase 3 experimentó una reducción en la asociación a ofrendas faunísticas.

Tras estos filtros sociales siguieron otros:

e) No todo animal susceptible de aprovechamiento económico fue considerado apto en el plano ritual: la fauna salvaje fue excluida sistemáticamente ${ }^{53}$. Además, entre los animales domésticos faltan équidos ${ }^{54} \mathrm{y}$ cánidos y apenas hay suidos y bovinos.

f) Ovejas y cabras, protagonistas del aporte cárnico cotidiano, fueron mayoritarias entre las ofrendas. En La Bastida, los porcentajes de ambas especies son similares; en La Almoloya, predominan las ovejas.

g) Se adivina una tendencia a sacrificar animales más jóvenes en La Almoloya que en La Bastida.

h) No toda parte anatómica fue considerada apta: siempre se seleccionaron extremidades, descartándose por completo cabeza y tronco. Sin embargo, no solían depositarse patas enteras sino solo partes, rara vez las de mayor aporte cárnico y contenido medular.

g) Cada asentamiento practicó los mismos criterios generales de selección (extremidades, sin las partes más carnosas), pero los materializó de forma distinta, diríase que opuesta: en La Almoloya, mayoría abrumadora de extremidades delanteras $(95,8 \%)$ y predominio de lateralidad izquierda (60,3\%); en La Bastida: mayoría abrumadora de extremidades traseras $(87,5 \%)$ y predominio de lateralidad derecha $(55,6 \%)$ (Anexo-Figs. 7 y 8 ).

\footnotetext{
53 Se han registrado dos excepciones: una porción de pata de cérvido en la tumba 9 de Los Cipreses (Martínez Rodríguez et al. 1999; Martínez Rodríguez y Ponce 2005) y otra en la tumba 62 de Fuente Álamo (Liesau y Schubart 2004).

${ }^{54}$ La única excepción es una porción de caballo en la tumba 69 de Fuente Álamo (Liesau y Schubart 2004).
}

j) La ubicación de las porciones en relación al cadáver ${ }^{55}$ pero, sobre todo, a los recipientes cerámicos, sugiere que eran asimiladas conceptualmente a la categoría "alimento", pese a que la fracción comestible asociada fuese exigua.

k) Las ofrendas de fauna trascienden categorías de riqueza. El ganado vacuno no era exclusivo de las tumbas más ricas aunque suelen preferirse estos animales, ausentes en los ajuares más pobres. Las ovejas pueden aparecer en cualquier ajuar. En cambio, probablemente, las cabras no se consideraron apropiadas en las ofrendas para la élite.

1) La ofrenda de porciones animales era independiente del sexo de la persona inhumada. El único patrón a este respecto es la exclusividad de porciones laterales izquierdas para los varones de La Almoloya.

\section{CONCLUSIONES}

La elevada frecuencia de ofrendas faunísticas en los ajuares funerarios argáricos y la variedad de sus expresiones invitan a ahondar en su sentido social. En rigor, la presencia de restos de fauna en una tumba indica el sacrificio de un animal y la inclusión, al menos, de una porción antes de clausurar la sepultura. Ello no implica necesariamente que se consumiera el resto del animal en una celebración colectiva con una elevada carga simbólica, durante la cual se hiciera partícipe del ágape a la persona fallecida. Suponer que las gentes argáricas celebraban banquetes en los que participaban imaginariamente las personas difuntas es más una asunción que una deducción e inaugura una cadena de inferencias que debería superar varios escollos.

a) Las porciones faunísticas depositadas, casi siempre extremidades incompletas, suelen aportar muy poca carne, con las únicas salvedades representadas por fémures, húmeros y las escápulas de mayor tamaño.

b) Los restos óseos no muestran indicios de cocinado.

c) Los conjuntos funerarios (contenedor, fosa o posibles estructuras) y depósitos arqueológicos asociados no incluyen acumulaciones de restos de consumo interpretables como resultado de celebraciones colectivas.

Por tanto, las evidencias arqueológicas no permiten afirmar que las donaciones de fauna estuvieron vinculadas con "banquetes fúnebres". De ahí que los estudios que vindican el concepto "comensalidad" requieren una reformulación de sus premisas de partida y una revisión de sus conclusiones. Ahora bien, uno de los resultados de nuestro análisis apunta a que las gentes

\footnotetext{
${ }_{55}$ Bien documentada en La Almoloya.
} 
argáricas conceptualizaban las ofrendas de fauna como "alimento", estableciendo una especie de sinécdoque de la parte (porción con poca carne) por el todo ("ración de comida" o "animal doméstico" como recurso alimenticio).

Los restos de fauna, en tanto indicadores de "alimento", siguen un itinerario distinto al de otros elementos del ajuar funerario. Ropa, adornos, utensilios y armas serían "propios" de la persona enterrada y aludirían a rasgos sociales relevantes en vida ("objetos de pertenencia”), mientras que fauna y recipientes cerámicos (potenciales contenedores de comida y bebida) serían donaciones "pertinentes" según el colectivo a cargo del funeral ("objetos de pertinencia"). Esta diferencia conceptual conlleva una distinción práctica: el grupo amortiza, es decir, "pierde" instrumentos, armas y adornos que podrían haber seguido en uso, pero, en cambio, el sacrificio de una cabeza de ganado supondría una "ganancia", habida cuenta que el consumo de carne no era habitual entre gran parte de la población (Knipper et al. 2020).

La asignación de porciones faunísticas fue una práctica muy frecuente y socialmente transversal, es decir, relativamente al margen de las diferencias socioeconómicas, socio-sexuales (del sistema sexo/género) y territoriales. Su elevada frecuencia y asociación indistinta a cualquier combinación de ajuar (presentándose incluso como el único elemento en las tumbas más pobres) permiten inferir que el valor económicosocial de la fauna en conjuntos funerarios fue bajo ${ }^{56}$. El condicionante socioeconómico se manifestaría en la preferencia hacia el ganado bovino por parte de la clase dominante $y$, eventualmente, miembros de la intermedia, aun cuando tampoco se seleccionó en exclusiva para sus integrantes. Prevalece, por tanto, la práctica interclasista del sacrificio de una cabeza de ganado y su previsible distribución, hasta el punto de que uno de los aspectos que quedan sin explicar es por qué cierto porcentaje de individuos adultos no mereció ninguna porción faunística al morir y por qué esta circunstancia se hizo más frecuente en la última fase argárica ( $c a$. 1750-1550 cal ANE).

Con escaso valor socioeconómico, el papel de las ofrendas faunísticas recae en la dimensión sociopolítica. Aproximarse a su significado requiere atender las peculiaridades de su expresión material. Ese significado no se limitaba a conceptos generales como "animal", "alimento" o "carne", sino a otros más concretos y, a la vez, más ricos. Así lo indica la selección casi exclusiva de ciertas porciones de extremidades de determinados animales domésticos, preferentemente ovejas y cabras,

\footnotetext{
${ }^{56}$ Como también lo era, p. ej., el de las vasijas de las formas 1 y 5 en el análisis de Lull y Estévez (1986).
}

con la consiguiente exclusión de otros incluidos en la dieta, como especies salvajes (cérvidos, jabalíes, lagomorfos, caprinos) y otras domésticas (équidos, cánidos), así como la preferencia hacia ovejas y cabras.

Sugerimos que las ofrendas faunísticas, más allá de referirse a la idea de "alimento", podrían representar simbólicamente derechos y/u obligaciones sociales de una parte sustancial de la población a partir de cierta edad. Ello sería independiente de la extracción socioeconómica y, en buena medida, del sexo, ya que la única asociación de esta índole se da entre los varones adultos de La Almoloya, cuyos cuerpos eran depositados preferentemente sobre el costado izquierdo (lo habitual entre los hombres argáricos), y donaciones de porciones faunísticas de lateralidad izquierda.

La sociedad argárica utilizaba el ritual funerario intramuros para representar dimensiones de sí misma, como sujeto. Recibir sepultura en un asentamiento designaba el mínimo común compartido por un grupo social, tal vez el único que, en propiedad, merecería la etiqueta de "argárico". A partir de esta denotación grupal, se desplegó un abanico de disposiciones rituales que distinguieron colectivos en función de dimensiones diversas. Así, Lull y Estévez (1986) advirtieron preferencias en la elección del contenedor entre las tierras litorales del sureste y las del interior, que experimentaron a su vez cambios diacrónicos (Castro et al. 1993-1994). Más allá de la "pertinencia" en la selección del tipo de tumba, la variabilidad en la composición de los ajuares abrió múltiples posibilidades para componer por adición, sintagmáticamente, enunciados que expresaban consideraciones sobre la edad al morir, el sexo y la condición económica. Desde esta perspectiva, el sintagma manifestado por la ofrenda de alimento (mediante cerámica y/o fauna) fue el que designó con más eficacia el adjetivo "argárico", solo superado en generalidad por la típica inhumación intramuros. En otras palabras, las comunidades argáricas reconocían la adscripción de sus miembros mediante el derecho al enterramiento y, a continuación, distinguían mediante la donación de comida una segunda condición de alcance social muy amplio, afín a un imaginario de adhesión colectiva o, cuando menos, mayoritaria.

El sintagma "alimento" subrayaba adscripción grupal; además, el significado de la ofrenda faunística se ampliaba mediante variación paradigmática: la selección de la porción (de extremidad delantera o trasera) demarcaba una preferencia o nueva "pertinencia" social, posiblemente del mismo orden territorial que la expresada en la elección del contenedor funerario.

Así pues, la adscripción simbólica al grupo siempre procedía por donación social: primero se "donaba" la tumba (el contenedor tampoco era "propio" de la persona fallecida) a modo de acto fundador, de condición de posibilidad de cualquier representación o mensaje

Trab. Prehist., 78, N. ${ }^{\circ} 1$, enero-junio 2021, pp. 104-120, ISSN: 0082-5638

https://doi.org/10.3989/tp.2021.12267 
y, después de depositar los cadáveres con su ajuar “de pertenencia" (si este fuese el caso), se ofrecía alimento a la mayoría de quienes hubiesen superado cierta edad. Desde esta perspectiva, las tumbas sin fauna ni cerámica en La Almoloya y La Bastida habrían acogido individuos reconocidos como "argáricos", pero carentes de refrendo social pleno. Cabe imaginar que para la mayoría, los de menor edad, la muerte prematura fue el principal factor que impidió un reconocimiento completo. En cambio, para los adultos es difícil encontrar una explicación satisfactoria: unos pocos fueron inhumados sin alimento, algunos merecieron un recipiente cerámico, pero ninguna porción animal. La mayoría, en cualquier caso, data de la Fase 3. El momento de apogeo argárico y, también, de máxima asimetría social, pudo haber conllevado la pérdida de ciertos derechos para parte de la población que los detentaba en la fase anterior.

Enunciados los dos grados de pertenencia grupal mediante inhumación intramuros y ofrenda alimentaria, la sociedad argárica codificaba la particularidad más "propia" de la persona fallecida, añadiendo sintagmáticamente complementos en función de edad, sexo y condición socioeconómica. La comunidad reconocía así el componente individualista que, paradójicamente, la negaba como tal. La fauna no se mantuvo al margen, sino que obró paradigmáticamente según un margen propio de variación: exclusión de las personas más pobres del ganado vacuno y asociación de infantiles a ovejas o cabras.

En resumen, las ofrendas faunísticas y, por extensión, las incluidas bajo la etiqueta "alimento" han resultado ser relevantes para adentrarnos en lo que podríamos denominar "prácticas de codificación social" argáricas. Su relativa abundancia mengua su valor económico, pero las sitúa como protagonistas del imaginario social.

\section{ANEXO. ARCHIVO COMPLEMENTARIO}

En la edición electrónica de este artículo, disponible en libre acceso en el sitio web de la revista, se incluye un archivo que contiene los criterios metodológicos para la descripción del material osteológico, así como las tablas y figuras referenciadas en este texto con la mención "Anexo".

\section{BIBLIOGRAFÍA}

Andúgar, L. 2015: "Fauna de La Bastida conservada en el Museo Arqueológico de Murcia”. En V. Lull, R. Micó, C. Rihuete Herrada y R. Risch: La Bastida (Totana, Murcia). La documentación de las intervenciones (1869-2005). Integral. Murcia: 1401-1469.
Andúgar, L. 2016: Análisis faunístico de los conjuntos calcolíticos y argáricos del yacimiento de Gatas (Turre, Almería) y La Bastida (Totana, Murcia). Tesis doctoral, Universitat Autònoma de Barcelona. Barcelona. https://hdl.handle.net/10803/385722

Aranda, G. 2008: "Cohesión y distancia social. El consumo comensal de bóvidos en el ritual funerario de las sociedades argáricas". Cuadernos de Prehistoria y Arqueología de la Universidad de Granada 18: 107-123.

Aranda, G. 2016: "Meat consumption as a social strategy: feeding new identities in Early Bronze Age societies in Iberia”. En R. Vilaça y M. Serra (eds.): Matar a fome, alimentar a alma, criar sociabilidades. Alimentação e comensalidades nas sociedades pré e proto-históricas. Universidad de Coimbra. Coimbra: 17-37.

Aranda, G. y Esquivel, J. A. 2006: "Ritual funerario y comensalidad en las sociedades de la Edad del Bronce del Sureste Peninsular: la cultura de El Argar". Trabajos de Prehistoria 63 (2): 117-133. https://doi.org/10.3989/tp.2006.v63.i2.20

Aranda, G. y Esquivel, J. A. 2007: "Poder y prestigio en las sociedades de la cultura de El Argar. El consumo comunal de bóvidos y ovicápridos en los rituales de enterramiento". Trabajos de Prehistoria 64 (2): 95118. https://doi.org/10.3989/tp.2007.v64.i2.111

Aranda, G. y Molina, F. 2006: "Wealth and power in the bronze age of the south-east of the Iberian peninsula: the funerary record of Cerro de la Encina". Oxford Journal of Archaeology 25 (1): 47-59.

Aranda, G. y Montón, S. 2011: "Feasting death: funerary rituals in the Bronze Age societies of South-Eastern Iberia". En G. Aranda, S. Montón y M. Sánchez Romero (eds.): Guess who's coming to dinner. Feasting rituals in the prehistoric societies of Europe and Near East. Oxbow Books. Oxford: 130-157.

Cámara, J. A. 2001: El ritual funerario en la Prehistoria Reciente en el Sur de la Península Ibérica. British Archaeological Reports International Series 913, BAR Publishing. Oxford.

Cámara, J. A. y Molina, F. 2009: "El análisis de la ideología de emulación: el caso de El Argar". Cuadernos de Prehistoria y Arqueología de la Universidad de Granada 19: 163-194.

Cámara, J. A. y Molina, F. 2011: "Jerarquización social en el mundo argárico (2000-1300 aC)". Quaderns de Prehistòria i Arqueologia de Castelló 29: 77-104.

Castro, P.; Chapman, R. W.; Gili, S.; Lull, V.; Micó, R.; Rihuete Herrada, C.... y Sanahuja, M. . E. 1993-1994: "Tiempos sociales de los contextos funerarios argáricos". Anales de Prehistoria de la Universidad de Murcia 9-10: 77-107.

Cereijo, M. 1992: "Las sepulturas de La Bastida de Totana". En M. ${ }^{a}$ M. García López: La Bastida de Totana. Estudio de materiales arqueológicos inéditos. Universidad de Murcia. Murcia: 207-210.

Cierva López, J. de la y Cuadrado Díaz, E. 1945: "Los descubrimientos argáricos en la Almoloya de Mula, Pliego (Murcia)". Anales de la Universidad de Murcia - Letras 3: 355-382.

Costa, C.; Bettencourt, A. M. S. y Senra, M. 2019: "The symbolic meaning of cattle and sheep/goat in the Bronze Age: faunal inclusions in funerary contexts of South-Western Iberia". International Journal of Osteoarchaeology 29: 602-612. https://doi.org/10.1002/oa.2756

Cuadrado Díaz, E. 1945a: "Un nuevo yacimiento argárico: La Almoloya (Murcia)". Boletín Arqueológico del Sudeste Español I-1: 89-90.

Cuadrado Díaz, E. 1945b: "La Almoloya, nuevo poblado de la cultura de El Argar”. Anales de la Universidad de Murcia - Letras 3: 355-382.

Garrido, R. 2012-2013: "Alcohol, prestigio y poder: ritos de comensalidad en el Campaniforme del interior peninsular (2500-2000 AC)". Boletín de la Asociación Española de Amigos de la Arqueología 47: 47-59.

Garrido, R.; Rojo, M. A; García-Martínez de Lagrán, Í. y Tejedor, C. 2011: "Drinking and eating together: the social and symbolic context of commensality rituals in the Bell Beakers of the interior of Iberia (2500-2000 cal BC)". En G. Aranda, S. Montón y M. Sánchez-Romero (eds.): Guess who is coming to dinner. Commensality rituals in the prehistoric societies of Europe and the Near East. Oxbow Books. Oxford: 109-129.

Inchaurrandieta, R. de. 1870: "Estudios Pre-Históricos. La Edad del Bronce en la prov. de Murcia". Boletín-Revista de la Universidad de Madrid II, 13: 806-815. 
Jameson, F. 1991: Posmodernism, or, the cultural Logic of Late Capitalism. Duke University Press. Durham.

Jover, F. J. y López Padilla, J. A. 2013: "La producción textil durante la Edad del Bronce en el cuadrante suroriental de la Península Ibérica: materias primas, productos, instrumentos y procesos de trabajo". Zephyrus 71: 149-171.

Knipper, C.; Rihuete Herrada, C.; Voltas, J.; Held, P.; Lull, V.; Micó, R... y Alt, K. W. 2020: "Reconstructing Bronze Age diets and farming strategies at the early Bronze Age sites of La-Bastida and Gatas (southeast Iberia) using stable isotope analysis". Plos One 15 (3): e0229398. https://doi.org/10.1371/journal.pone.0229398

Kunter, H. 2000: "Los restos de esqueletos humanos hallados en Fuente Álamo durante las campañas de 1985, 1988 y 1991". En H. Schubart, V. Pingel y O. Arteaga (eds.): Fuente Álamo. Las excavaciones arqueológicas 1977-1991 en el poblado de la Edad del Bronce. Serie Arqueología Monografías Memorias 8. Junta de Andalucía. Sevilla: 265-282.

Kunter, H. 2004: "III. Die menschlichen Skelettreste aus den Grabungskampanien 1996 und 1999 in Fuente Álamo". En M. Pozo, M. Kunter; J. A. Medina; C. Liesau; J. Casas; H. Schubart.... I. Hägg: "Studien zum Grab 111 der Nekropole von Fuente Álamo (Almería)". Madrider Mitteilungen 45: 88-96.

Liesau, C. y Schubart, H. 2004: "IV. Grabanlagen und Beigaben aus Organischem Material im Bestattungsritus von Fuente Álamo". En M Pozo, M. Kunter, J. A. Medina, C. Liesau, J. Casas, H. Schubart.... I. Hägg: "Studien zum Grab 111 der Nekropole von Fuente Álamo (Almería)". Madrider Mitteilungen 45: 97-107.

López Padilla, J. A. 2006: "Distribución territorial y consumo de botones de perforación en "V" en el ámbito argárico". Trabajos de Prehistoria 63 (2): 93-116. https://doi.org/10.3989/tp.2006.v63.i2.19

Lull, V. 2007: Los objetos distinguidos. La arqueología como excusa. Bellaterra. Barcelona.

Lull, V. 2016: "Muerte y espectáculo en arqueología". MARQ, Arqueología y Museos 7: 11-17.

Lull, V. y Estévez, J. 1986: "Propuesta metodológica para el estudio de las necrópolis argáricas”. En Homenaje a Luis Siret (1934-1984). Junta de Andalucía, Sevilla: 441-452

Lull, V.; Micó, R.; Rihuete Herrada, C. y Risch, R. 2005: "Property relations in the Bronze Age of southwestern Europe: An archaeological analysis of infant burials from El Argar (Almería, Spain)". Proceedings of the Prehistoric Society 71: 247-268.

Lull, V.; Micó, R.; Rihuete Herrada, C. y Risch, R. 2011: "Proyecto La Bastida": economía, urbanismo y territorio de una capital argárica". Verdolay 13: 57-70.

Lull, V.; Micó, R.; Rihuete Herrada, C. y Risch, R. 2014: “The La Bastida fortification system: new light and new questions on the Early Bronze Age societies in the Western Mediterranean". Antiquity 340: 395-410.
Lull, V.; Micó, R.; Rihuete Herrada, C. y Risch, R. 2015a: Primeras investigaciones en La Bastida (1869-2005) I. Integral-Sociedad para el Desarrollo Rural. Murcia.

Lull, V.; Micó, R.; Rihuete Herrada, C. y Risch, R. 2015b: La Bastida y Tira del Lienzo (Totana,-Murcia). Ruta Argárica. Guías Arqueológicas. Integral. Murcia.

Lull, V.; Micó, R.; Rihuete Herrada, C. y Risch, R. 2016: “Argaric sociology: sex and death".-Complutum 27 (1): 31-62.

Lull, V.; Micó, R.; Rihuete Herrada, C.; Risch, R.; Celdrán, E.; Fregeiro, M. ${ }^{a}$ I.... y Velasco, C. 2015c: La Almoloya (Pliego, Murcia). Ruta Argárica. Guías Arqueológicas. Integral, Murcia.

Lull, V.; Micó, R.; Rihuete Herrada, C.; Risch, R. y Escanilla, N. 2017: "Halberdiers and combat systems in the Argaric". Oxford Journal of Archaeology 36 (4): 375-394.

Martínez Rodríguez, A.; Ponce, J. y Ayala, M. a M. 1999: "Excavaciones de urgencia del poblado argárico de Los Cipreses, Lorca. Años 19921993”. Memorias de Arqueología, 8: 155-182.

Martínez Rodríguez, A. y Ponce, J. 2005: "Evidencia de la metalurgia argárica en Lorca: el enterramiento de un hombre del poblado de Los Cipreses (Lorca, Murcia)". En M. Pérez Moya (ed.): Patrimonio Minero de la Región de Murcia. Bocamina. Murcia: 29-37.

Molina, E. 2015: La producción cerámica en el sudeste de la península ibérica durante el III y el II milenio ane (2200-1550 cal ANE): integración del análisis de residuos orgánicos en la caracterización funcional de los recipientes argáricos. Tesis doctoral, Universitat Autònoma de Barcelona. Barcelona https://www.tdx.cat/handle/10803/294607

Molina, F.; Rodríguez Ariza, M. ${ }^{a}$ O.; Jiménez Brobeil, S. y Botella, M. 2003: "La sepultura 121 del yacimiento argárico de El Castellón Alto (Galera, Granada)". Trabajos de Prehistoria 60 (1): 153-158. https://doi.org/10.3989/tp.2003.v60.i1.127

Parras, D. J.; Sánchez, A.; Ramos, N.; Rodríguez Ariza, M. a O. y Tuñón, J. A. 2011: "Identification of fats ans beeswax in ceramic vessels of tomb 121 of Castellón Alto (Galera, Granada)". Collution 22: 7-13.

Roberts, S. J.; Smith, C. I.; Millard, A. y Collins, M. J. 2002: "The taphonomy of cooked bone: Characterizing boiling and its physicochemical effects". Archaeometry 44 (3): 485-494.

Schubart, H. 2012: Die Gräber von Fuente Álamo. Ein Beitrag zu den Grabriten und zur Chronologie der El Argar-Kultur. Madrider Beiträge 32, Deutsches Archäologisches Institut Madrid-Reichert, Wiesbaden.

Siret, H. y Siret, L. 1887: Les premiers ages du métal dans le Sud-Est de l'Espagne: résultats des fouilles faites par les auteurs de 1887 á 1887. Imprimerie de Charles Peeters, Impr. Paul Godenne. Amberes, Bélgica.

Trab. Prehist., 78, N. ${ }^{\circ} 1$, enero-junio 2021, pp. 104-120, ISSN: 0082-5638

https://doi.org/10.3989/tp.2021.12267 